\title{
CHAGAS' DISEASE IN BOLIVIA: CLINICAL AND EPIDEMIOLOGICAL FEATURES AND ZYMODEME VARIABILITY OF TRYPANOSOMA CRUZI STRAINS ISOLATED FROM PATIENTS
}

\author{
S. F. BRENIĖRE, R. CARRASCO, S. REVOLLO, G. APARICIO, \\ P. DESJEUX, AND M. TIBAYRENC \\ ORSTOM, Montpellier Cedex, France; IBBA, La Paz, Bolivia; and World Health Organization, \\ Geneva, Switzerland
}

\begin{abstract}
We performed serological and pathological studies on 495 patients with Chagas' disease from different areas of Bolivia. Eighty-nine Trypanosoma cruzi strains, isolated by xenodiagnosis, were characterized by 12 isoenzyme loci and were related to the presence of cardiac changes and enteric disease with megacolon. There was a high heterogeneity of human zymodemes, presenting evidence of 2 predominant zymodemes genetically dissimilar from each other and ubiquitous in Bolivia. The frequencies of these predominant zymodemes among strains from patients were compared to strains from triatomine bugs previously studied. We observed mixtures of different zymodemes within the same patient, a phenomenon seen previously in Bolivian patients. There was no apparent difference of pathogenicity between the 2 more frequent zymodemes isolated from humans.
\end{abstract}

Trypanosoma cruzi, the agent of Chagas' disease, is associated with 2 main clinical forms, cardiac and intestinal. These clinical forms are not equally distributed within the geographical range of the disease, and it has been proposed that $T$. cruzi zymodeme distribution could explain this fact. ${ }^{1}$ We present here pathological, serological, and parasitological studies, involving 495 patients from Bolivia, showing the diversity of the clinical forms and the distributions of these clinical forms and $T$. cruzi zymodemes isolated from human. The relationships are presented and discussed.

\section{MATERIALS AND METHODS}

\section{Patients}

Two groups were examined at different times and under different conditions. Group I, consisting of 364 patients, was from the villages of Chiwisivi (Department La Paz) at 2,800 meters above sea level (mas), Salinas (Department Santa-Cruz) at 800 mas, and Camiri (Department Santa-Cruz) at 800 mas (Table 1). After clinical examination, electrocardiography was performed. Serodiagnostic procedures included indirect immunofluorescence IgG (IMF), and ELISA. ${ }^{2}$ These patients were then classified as follows, according to the results of these tests:
Positive serology and positive cardiopathyIMF and ELISA tests positive, ECG with abnormalities as in Groups II and III of the WHO classification. ${ }^{3}$

Positive serology and negative cardiopathyIMF and ELISA tests positive, normal ECG.

Negative serology and positive cardiopathyIMF and ELISA tests negative, ECG with abnormalities as in Groups II and III of the WHO classification. $^{3}$

Negative serology and negative cardiopathyIMF and ELISA tests negative, normal ECG.

The second group was composed of 131 patients, all exhibiting a positive serology (serodiagnosis as noted above). They originated from different endemic regions of Bolivia, although 108 had been living in $\mathrm{La} \mathrm{Paz}$ (3,600 mas) for at least 5 years (average time spent in La Paz: 10 years). The endemic areas where the patients had spent their childhoods or the first endemic area where they had spent $>1$ year were considered the geographical origins of infection (Table 2). The following tests were conducted: ECG, $x$-ray of the right anterior side of the esophagus, and $\mathrm{x}$-ray of colon after barium washing ( $4 \mathrm{x}$-ray films. Group II patients were then classified as follows:

Asymptomatic-positive serology, normal ECG, normal esophagus and colon.

Cardiopathy-positive serology, ECG with 
TABLE 1

Serology, cardiac pathology, and zymodemes of Group I patients by locality

\begin{tabular}{|c|c|c|c|c|c|c|c|}
\hline \multirow[b]{2}{*}{ Localities } & \multirow[b]{2}{*}{ Sex } & \multirow[b]{2}{*}{$\mathrm{n}$} & \multicolumn{2}{|c|}{ Positive serology } & \multicolumn{2}{|c|}{ Negative serology } & \multirow[b]{2}{*}{ Zymodemes* } \\
\hline & & & $\mathrm{C}+\dagger$ & $\mathrm{C}-\frac{1}{7}$ & $\overline{C+}$ & $\mathrm{C}-$ & \\
\hline Chiwisivi & $\mathrm{M}$ & 113 & 27 & 37 & 11 & 38 & 9 \\
\hline \multirow[t]{2}{*}{ Salinas } & $\mathrm{M}$ & 24 & 7 & 16 & 0 & 1 & \\
\hline & $\mathbf{F}$ & 22 & 6 & 15 & 0 & 1 & - \\
\hline \multirow[t]{2}{*}{ Camiri } & $\mathbf{M}$ & 88 & 13 & 63 & 0 & 12 & $2,37,38,39,42$ \\
\hline & $\mathrm{F}$ & 117 & 17 & 71 & 0 & 29 & \\
\hline Total & & 364 & \multicolumn{2}{|c|}{$272(74.7 \%)$} & \multicolumn{2}{|c|}{$92(25.3 \%)$} & \\
\hline
\end{tabular}

* After Tibayrenc and others ${ }^{8.12}$; zymodemes isolated from Triatoma infestans.

$\dagger \mathrm{C}+=\mathrm{ECG}$ presenting abnormalities Groups II and III of the WHO classification. ${ }^{3}$

$\neq \mathrm{C}-\mathrm{=}$ Normal ECG.

abnormalities as in Group II and III of the WHO classification, ${ }^{3}$ normal esophagus and colon.

Megacolon - positive serology, colon with abnormal length (DI, DII, or DIII, according to the degree of hypertrophy) and/or enlargement (MI, MII, or MIII, according to the degree of hypertrophy), normal ECG, normal esophagus. The abnormal length of the colon (DI) observed in the patients having spent $>5$ years in highland was considered insignificant because this is frequently seen in individuals living in highlands (La Paz, 3,800 mas; Cochabamba and Sucre, 2,600 mas).

Megaoesophagus-esophagus with abnormal dilatation, ${ }^{4}$ normal ECG and colon.

Associated-positive serology, ECG with abnormalities, and megaoesophagus and/or megacolon as mentioned above.

\section{Zymodeme sampling}

By drawn xenodiagnosis, 35 strains were isolated from patients of the Group II; 10 others were isolated from patients who had ECG exam only, and 44 others were isolated from patients who had not been examined otherwise. All patients originated from various Bolivian endemic areas (Table 3) and all presented a positive serology.

\section{Zymodeme identification}

T. cruzi strains were isolated by xenodiagnosis using a method previously described. ${ }^{5}$ The xenodiagnosis was performed with 30 laboratoryreared Triatoma infestans (third larval stage). Strains of $T$. cruzi from these patients were grown in LIT medium. Eleven enzyme systems corresponding to 12 genetic loci were assayed: glucose6-phosphate dehydrogenase (E.C.1.1.1. 49, G6PD), glucose-6-phosphate isomerase (E.C.5.3.1.9., GPI), glutamate dehydrogenase $\mathrm{NAD}+$ (E.C.1 4.1.2., GDH-NAD+), glutamate dehydrogenase NADP+ (E.C.1.4.1.4., GDHNADP + ), isocitrate dehydrogenase (E.C.1.1.1.42, IDH), malate dehydrogenase (E.C.

TABLE 2

Pathologies of 131 chronic Bolivian chagasic patients from various endemic areas

\begin{tabular}{|c|c|c|c|c|c|c|}
\hline \multirow{2}{*}{$\begin{array}{l}\text { Geographical } \\
\text { origin of } \\
\text { patients }\end{array}$} & \multirow[b]{2}{*}{$\mathbf{n}$} & \multicolumn{5}{|c|}{ Clinical groups* } \\
\hline & & A & $\mathrm{C}$ & $\mathrm{MC}$ & MO & AS \\
\hline Camargo & 1 & 1 & 0 & 0 & 0 & 0 \\
\hline Camiri & 4 & 3 & 0 & 1 & 0 & 0 \\
\hline Cochabamba & 34 & $15(44.1 \%)$ & $7(20.5 \%)$ & $10(29.4 \%)$ & $0(0 \%)$ & $2(5.8 \%)$ \\
\hline Potosi & 5 & 3 & 1 & 1 & 0 & 0 \\
\hline Santa-Cruz & 1 & 2 & 3 & 5 & 0 & 0 \\
\hline Sucre & 38 & $20(52.6 \%)$ & $8(21 \%)$ & $6(15.8 \%)$ & $0(0 \%)$ & $6(15.8 \%)$ \\
\hline Tarija & 7 & 2 & 0 & 4 & 0 & 1 \\
\hline Tupiza & 9 & 2 & 4 & 3 & 0 & 0 \\
\hline Valle Grande & 5 & 3 & 1 & 0 & 1 & 0 \\
\hline Yungas & 7 & 4 & 0 & 3 & 0 & 0 \\
\hline Undetermined & 9 & 4 & 2 & 2 & 0 & 1 \\
\hline Total & 131 & $59(45 \%)$ & $26(19.8 \%)$ & $35(26.7 \%)$ & $1(0.07 \%)$ & $10(7.6 \%)$ \\
\hline
\end{tabular}

All of these patients were examined in La Paz and presented a positive serology.

* $\mathrm{A}=$ asymptomatic, $\mathrm{C}=$ cardiopathy, $\mathrm{MC}=$ megacolon, $\mathrm{MO}=$ megaoesophagus, and $\mathrm{AS}=$ associated. 
TABLE 3

Numbers of patients infected by given zymodemes, or mixtures of zymodemes, with reference to their geographical origin

\begin{tabular}{|c|c|c|c|c|c|c|c|c|c|c|c|c|c|}
\hline \multirow[b]{2}{*}{$\begin{array}{l}\text { Geographical } \\
\text { origin of } \\
\text { patients }\end{array}$} & \multirow[b]{2}{*}{$\mathbf{n}$} & \multicolumn{8}{|c|}{ Only one zymodeme } & \multicolumn{4}{|c|}{$\begin{array}{l}\text { Two zymodemes within } \\
\text { the same patient }\end{array}$} \\
\hline & & NP1 & 7 & 19 & $\frac{1}{20}$ & 32 & 39 & 40 & 43 & NP2 & $\begin{array}{c}20+ \\
39\end{array}$ & $\begin{array}{c}20+ \\
40\end{array}$ & $\begin{array}{c}7+ \\
20\end{array}$ \\
\hline Cochabamba & 33 & 0 & 1 & 2 & 6 & 0 & 22 & 0 & 0 & 0 & 1 & 1 & 0 \\
\hline Potosi & 3 & 1 & 0 & 0 & 1 & 0 & 1 & 0 & 0 & 0 & 0 & 0 & 0 \\
\hline Santa-Cruz & 10 & 0 & 0 & 2 & 0 & 0 & 6 & 1 & 0 & 0 & 1 & 0 & 0 \\
\hline Sucre & 16 & 0 & 1 & 4 & 2 & 1 & 6 & 0 & 0 & 0 & 2 & 0 & 0 \\
\hline Tarija & 1 & 0 & 0 & 0 & 1 & 0 & 0 & 0 & 0 & 0 & 0 & 0 & 0 \\
\hline Tupiza & 2 & 0 & 0 & 0 & 1 & 0 & 1 & 0 & 0 & 0 & 0 & 0 & 0 \\
\hline Valle Grande & 1 & 0 & 0 & 0 & 1 & 0 & 0 & 0 & 0 & 0 & 0 & 0 & 0 \\
\hline Yungas & 2 & 0 & 0 & 0 & 0 & 0 & 0 & 0 & 0 & 0 & 1 & 0 & 1 \\
\hline Unknown & 21 & 0 & 0 & 3 & 6 & 0 & 5 & 0 & 2 & 1 & 4 & 0 & 0 \\
\hline Total & 89 & 1 & 1 & 11 & 18 & 1 & 41 & 1 & 2 & 1 & 9 & 1 & 1 \\
\hline
\end{tabular}

NP $=$ new profile.

Zymodeme numbering is according to Tibayrenc and others. ${ }^{8}$

1.1.1.37, $\mathrm{MDH}$ ), malate dehydrogenase (oxaloacetate decarboxylating, NADP+), or malic enzyme (E.C.1.1.1 40, ME), peptidase 1 (Ficin) (E.C.3.4.22.3., formerly E.C.3.4.4.12, PEP-1, substrate: Leucyl-leucyl-leucine), peptidase 2 (Bromelain) (E.C.3.4.22.4., formerly E.C.3.4.4.24, PEP-2, substrate: Leucyl-L-alanine), phosphoglucomutase (E.C.5.4.2.2., formerly E.C.2.7. 5.1., PGM), and 6-phosphogluconate dehydrogenase (E.C.1.1.1.44, 6PGD). Electrophoreses were performed on cellulose acetate plates using the method of Tibayrenc and others $^{6}$ with slight modifications. Genetic interpretation of the zymograms and zymodeme numbering were performed as previously described. ${ }^{7,8}$

\section{Statistical methods}

The chi-square $\left(\chi^{2}\right)$ test or the modified $\chi^{2}$ test (small samples) were used for the different comparisons. The phylogenetic relationships among the zymodemes evidenced have been evaluated by calculation of Nei's standard genetic distance ${ }^{9}$ (measure of the number of codon differences per gene between 2 populations) and by the minimum-length Wagner network clustering method. ${ }^{8,10,11}$

\section{RESULTS}

Serological and electrographic study of Group I patients

The study of 364 patients from 3 endemic areas revealed high rates of positive serology, ranging from $56.6 \%$ in Chiwisivi to $95.6 \%$ in Salinas. Women from Camiri presented a significantly higher number of positive serologies than men $\left(\chi^{2}=3.89, \mathrm{df}=1, P<0.05\right)$; this result was not observed in Salinas. Men from Chiwisivi exhibited a significantly lower rate of positive serology than men from Camiri and Salinas $\left(\chi^{2}=20.66\right.$, $P<1 \mathrm{O}^{-3}$ and $\chi^{2}=13.12, P<1 \mathrm{O}^{-3}$, df $=1$, respectively). The difference observed between Camiri and Salinas was not statistically significant $(0.85, P>0.05)$. High rates of ECG abnormalities in the whole populations were observed (Table 1): $14.6 \%$ in Camiri, $28.2 \%$ in Salinas, and $33.6 \%$ in Chiwisivi. In Camiri and Salinas, ECG abnormalities were constantly associated with positive serology. In contrast, in Chiwisivi, 11 patients with negative serology presented ECG abnormalities, although there was a significant association between positive serology and cardiopathy $\left(\chi^{2}=5.22, \mathrm{df}=1, P<\right.$ 0.05 ). Among the patients exhibiting a positive serology, the index of cardiopathy was higher in Chiwisivi than in Salinas, and higher in Salinas than in Camiri (statistically significant for Chiwisivi and Camiri only $\left[\chi^{2}=10.71, \mathrm{df}=1, P<\right.$ $\left.10^{-2}\right]$ ).

\section{Clinical forms observed in Group II patients}

Table 2 summarizes the differences within Group II. Only 1 case of megaoesophagus without cardiac change was identified $(0.07 \%)$. Considering the different clinical forms (asymptomatic, cardiac, digestive, and associated), no significant difference was observed between pa- 


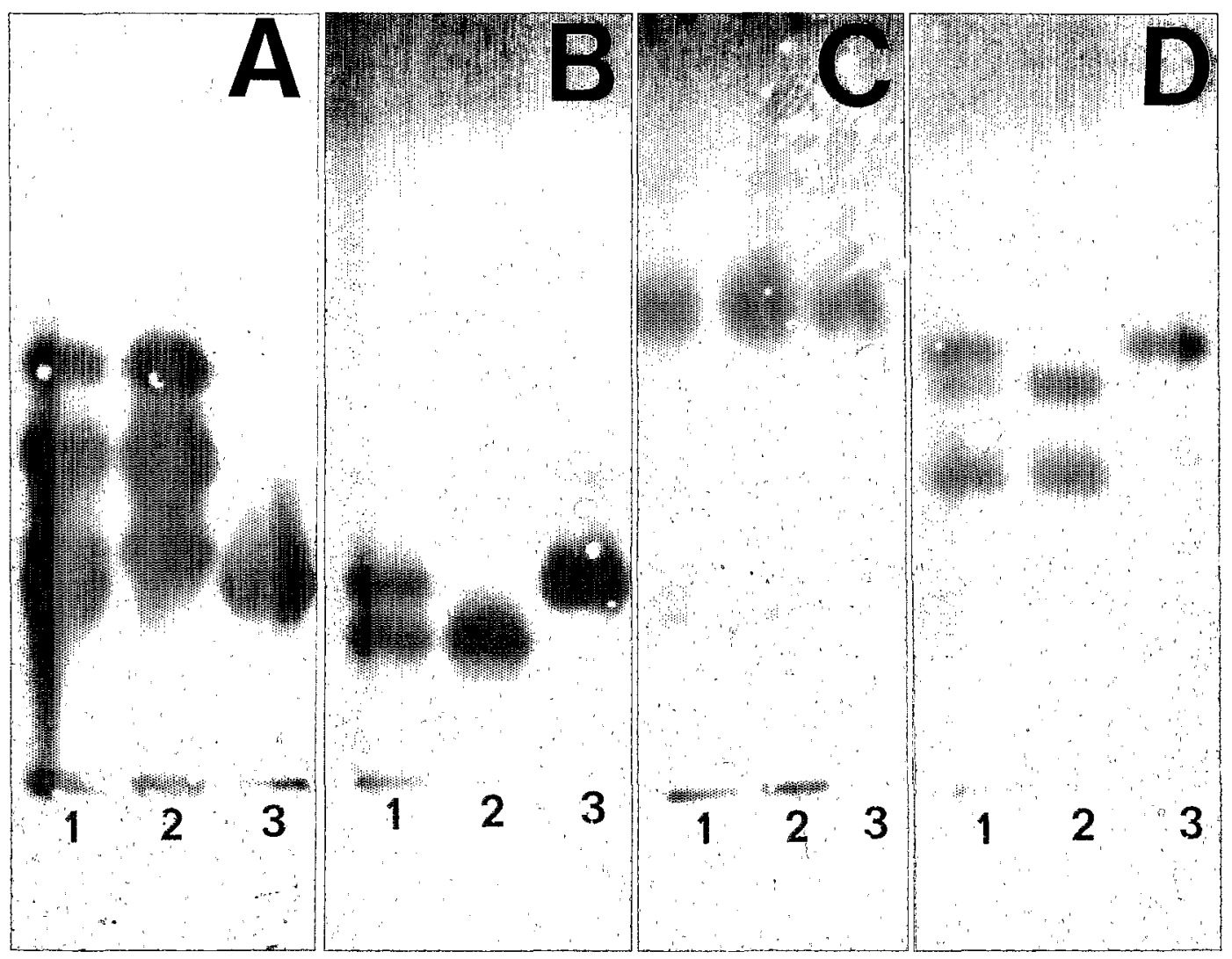

FIGURE 1. Electrophoretic profiles of 3 strains of $T$. cruzi isolated from patients by xenodiagnosis. Enzyme systems shown are (A) GPI, (B) IDH, (C) ME, and (D) PGM. Lanes 2 and 3 show strains isolated from 2 xenodiagnosis triatomine bugs from a single patient (typical patterns of zymodemes 39 and 20, respectively). Lanes 1 show stock isolated from a single xenodiagnosis triatomine bug from a single patient (typical pattern of a mixture of zymodemes 39 and 20 ).

tients infected either in Cochabamba or Sucre. Samples from others cities were too small for comparisons. Among the patients who presented with gastrointestinal changes, $42.2 \%$ had a severe megacolon (Grade III), $50.3 \%$ had a moderate megacolon (Grade II), and 7.5\% had a megacolon with minor changes (Grade I). The different frequencies of cardiac abnormalities were as follows: Bradycardia, 63.8\%; right branch block, $50 \%$; left anterior hemiblock, $38.8 \%$; ventricular premature beat, $8.3 \%$; and incomplete right bundle branch block, ischemia, and atrial fibrillation, $2.7 \%$ each. Of these patients, $36 \%$ presented with 2 associated cardiac abnormalities, while $16.6 \%$ presented with 3 associated abnormalities. Two patients had pacemaker devices related to Chagas cardiopathy.

\section{Zymodeme variability of $\mathrm{T}$. cruzi strains isolated from humans}

T. cruzi zymodemes identified among strains isolated from 89 Bolivian patients are presented in Table 3. Eleven patients from this sample $(12.3 \%)$ presented with mixed infections of 2 different zymodemes. These existed within 2 different sets of circumstances: a typical mixed isoenzyme pattern (which could be checked for 4 enzyme systems) of 1 stock isolated from 1 xenodiagnosis triatomine bug from a single patient, and 2 different isoenzymic patterns in 2 strains from 2 xenodiagnosis triatomine bugs from a single patient (Fig. 1). In the present sample, 9 different zymodemes (the genotypes of which are presented in Table 4) were identified. Seven zym- 
TABLE 4

Genotypes of Bolivian zymodemes isolated from humans identified by assaying 12 isozyme loci

\begin{tabular}{cccccccccccc}
\hline & \multicolumn{10}{c}{ Locus and genotype } \\
\cline { 2 - 13 } Zymodeme & G6pd & Gpi & Gdh-1 & Gdh-2 & Idh & Me-1 & Me-2 & Pep-1 & Pep-2 & Pgm & $6 p g d$ \\
\hline NP1† & $5 / 5$ & $5 / 5$ & $3 / 3$ & $2 / 2$ & $1 / 1$ & $2 / 2$ & $4 / 4$ & $3 / 3$ & $1 / 1$ & $3 / 3$ & $4 / 4$ \\
7 & $6 / 6$ & $5 / 5$ & $3 / 3$ & $2 / 2$ & $1 / 1$ & $2 / 2$ & $4 / 4$ & $1 / 1$ & $1 / 1$ & $3 / 3$ & $4 / 4$ \\
19 & $5 / 5$ & $5 / 5$ & $3 / 3$ & $2 / 2$ & $1 / 1$ & $2 / 2$ & $4 / 4$ & $1 / 1$ & $1 / 1$ & $3 / 3$ & $4 / 4$ \\
20 & $5 / 5$ & $5 / 5$ & $3 / 3$ & $2 / 2$ & $1 / 1$ & $2 / 2$ & $4 / 4$ & $1 / 1$ & $1 / 1$ & $3 / 3$ & $2 / 4$ \\
32 & $2 / 2$ & $3 / 3$ & $2 / 2$ & $5 / 5$ & $2 / 2$ & $2 / 2$ & $6 / 6$ & $5 / 5$ & $1 / 1$ & $10 / 12$ & $1 / 1$ \\
39 & $4 / 4$ & $2 / 4$ & $1 / 1$ & $1 / 1$ & $2 / 2$ & $1 / 1$ & $5 / 5$ & $5 / 5$ & $1 / 1$ & $6 / 10$ & $1 / 4$ \\
40 & $4 / 4$ & $3 / 4$ & $1 / 1$ & $1 / 1$ & $2 / 2$ & $1 / 1$ & $5 / 5$ & $4 / 4$ & $1 / 1$ & $4 / 11$ & $1 / 4$ \\
43 & $3 / 3$ & $3 / 4$ & $2 / 2$ & $4 / 4$ & $2 / 2$ & $1 / 1$ & $5 / 5$ & $4 / 4$ & $1 / 1$ & $4 / 11$ & $1 / 4$ \\
NP2 & $6 / 6$ & $5 / 5$ & $3 / 3$ & $4 / 4$ & $1 / 1$ & $3 / 3$ & $4 / 4$ & $-\ddagger$ & $1 / 1$ & $4 / 4$ & $2 / 4$ \\
\hline
\end{tabular}

* Zymodeme numbering according to Tibayrenc and others. ${ }^{8}$

$\dagger$ This zymodeme differed from zymodeme 2 by 1 locus: genotype $5 / 5$ for G6pd instead of $6 / 6$.

+ New electrophoretic position located between bands corresponding to genotypes $1 / 1$ and $2 / 2$.

NP $=$ new profile.

For each locus, allele 1 codes for the fastest electromorph. Mdh is not listed because it is monomorphic within this sample (genotype $2 / 2$ ).

odemes had been previously described, ${ }^{8}$ and 2 had never been observed before; 1 of the latter appeared to be closely related to zymodeme $2,{ }^{8}$ with 2 allelic differences out of 24 alleles distinguishable using 12 enzyme loci. The other zymodeme appeared to be related to zymodeme $6^{8}$ ( 6 allelic differences out of 24 alleles) (Table 4). We do not give any numbers to these new zymodemes, since their phylogenic relationship to those formerly described have to be assayed for a broader range of isozyme loci. In this sample, the most frequent zymodemes were 19,20, and $39,{ }^{8}$ which were already recorded in triatomine bugs sampled from various regions of Bolivia (Cochabamba, Sucre, Santa-Cruz), ${ }^{12}$ and which have been observed in wide geographical ranges in South America. 7,8

The genetic and patristic ${ }^{8,10,11}$ (or evolution-

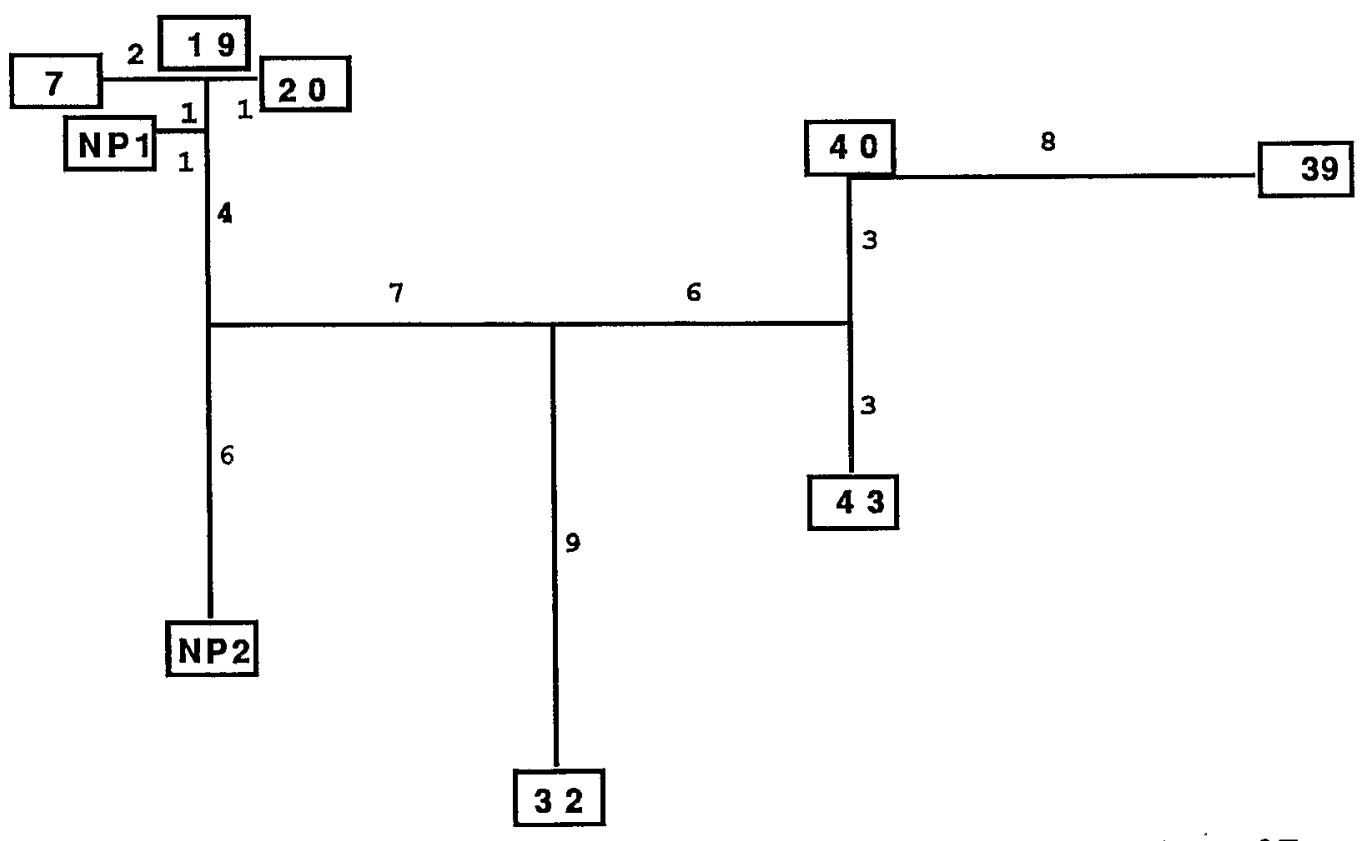

FIGURE 2. A minimum-length unrooted Wagner network of 51 steps linking the 9 zymodemes of $T$. cruzi identified in the present study. The boxed numbers correspond to the zymodemes, according to the numbering of Tibayrenc and others. ${ }^{8}$ The numbers along the branches are the patristic (or evolutionary) distances among the zymodemes. 
TABLE 5

Matrix of patristic (above the diagonal) and genetic (below the diagonal) distances among $9 \mathrm{~T}$. cruzi zymodemes isolated from 89 Bolivian patients using 12 isoenzyme loci

\begin{tabular}{cccccccccc}
\hline & \multicolumn{10}{c}{ Zymodeme } \\
\cline { 2 - 10 } Zymodeme & NP1 & 7 & 19 & 20 & 32 & 39 & 40 & 43 & NP2 \\
\hline NP1 & - & 4 & 2 & 3 & 21 & 29 & 21 & 21 & 11 \\
7 & 0.18 & - & 2 & 3 & 23 & 31 & 23 & 23 & 13 \\
19 & 0.08 & 0.08 & - & 1 & 21 & 29 & 21 & 21 & 11 \\
20 & 0.13 & 0.13 & 0.02 & - & 24 & 30 & 22 & 22 & 12 \\
32 & 1.36 & 1.36 & 1.36 & 1.34 & - & 26 & 18 & 18 & 22 \\
39 & 1.60 & 1.60 & 1.60 & 1.58 & 0.89 & - & 8 & 14 & 30 \\
40 & 1.60 & 1.60 & 1.60 & 1.58 & 1.14 & 0.18 & - & 6 & 22 \\
43 & 1.60 & 1.60 & 1.60 & 1.58 & 1.14 & 0.60 & 0.37 & - & 22 \\
NP2 & 0.54 & 0.39 & 0.54 & 0.52 & 1.65 & 1.49 & 1.29 & 0.98 & - \\
\hline
\end{tabular}

ary) distances observed among zymodemes are given in Table 5. The Wagner network ${ }^{8.10 .11}$ depicting their phylogenic relationships is shown in Figure 2.

\section{Zymodemes and pathologies}

Among patients presenting with a given anatomic picture and infected by only 1 zymodeme, a statistical analysis was carried out for checking the possible association between anatomic changes and the more frequent $T$. cruzi zymo- demes found in our study: we plotted into 1 group those patients infected with either zymodemes 7,19 , or 20 , since these zymodemes are closely related to each other. ${ }^{8}$ The second group was composed of patients infected with zymodeme 39 , which is radically dissimilar from zymodemes 7,19 , and $20{ }^{8}$ The other zymodemes were scarcely sampled, which made their use for statistical analyses impossible. Table 6 summarizes the pathologies observed in the 2 groups of patients defined above.

Several patients from these 2 different sets pre-

TABLE 6

Numbers of patients infected by given zymodemes by clinical form

\begin{tabular}{|c|c|c|c|c|}
\hline \multirow[b]{2}{*}{ Clinical groups } & \multirow[b]{2}{*}{ ECG abnormalities* } & \multirow[b]{2}{*}{ Megacolon $\dagger$} & \multicolumn{2}{|c|}{ Zymodemes $\ddagger$} \\
\hline & & & 7,19, or 20 & 39 \\
\hline Asymptomatic $(\mathrm{n}=11)$ & $\mathrm{N}$ & $\mathrm{N}$ & 6 & 5 \\
\hline Cardiac $(n=10)$ & $\begin{array}{l}\text { B } \\
\text { LAH } \\
\text { VPB } \\
\text { RBBB } \\
\text { LAH + B } \\
\text { RBBB + B } \\
\text { RBBB + LAH }\end{array}$ & $\begin{array}{l}\mathrm{N} \\
\mathrm{N} \\
\mathrm{N} \\
\mathrm{N} \\
\mathrm{N} \\
\mathrm{N} \\
\mathrm{N}\end{array}$ & $\begin{array}{l}2 \\
1 \\
0 \\
1 \\
0 \\
1 \\
1\end{array}$ & $\begin{array}{l}1 \\
1 \\
1 \\
0 \\
1 \\
0 \\
0\end{array}$ \\
\hline Megacolon $(n=6)$ & $\begin{array}{l}\mathrm{N} \\
\mathrm{N} \\
\mathrm{N}\end{array}$ & $\begin{array}{l}\text { DI } \\
\text { DII } \\
\text { DIII }\end{array}$ & $\begin{array}{l}1 \\
3 \\
1\end{array}$ & $\begin{array}{l}0 \\
1 \\
0\end{array}$ \\
\hline Associated $(\mathrm{n}=3)$ & $\begin{array}{l}\mathrm{B} \\
\mathrm{RBBB}+\mathrm{AF}+\mathrm{VPB} \\
\mathrm{RBBB}+\mathrm{LAH}\end{array}$ & $\begin{array}{l}\text { DII } \\
\text { MI, DIII } \\
\text { DII }\end{array}$ & $\begin{array}{l}1 \\
1 \\
1\end{array}$ & $\begin{array}{l}0 \\
0 \\
3\end{array}$ \\
\hline Not classified $(n=7)$ & $\begin{array}{l}\mathrm{N} \\
\text { RBBB } \\
\text { AVB + B }\end{array}$ & $\begin{array}{l}\text { not done } \\
\text { not done } \\
\text { not done }\end{array}$ & $\begin{array}{l}3 \\
1 \\
0\end{array}$ & $\begin{array}{l}2 \\
0 \\
1\end{array}$ \\
\hline Total $(n=37)$ & & & 24 & 16 \\
\hline
\end{tabular}

${ }^{*} \mathrm{~N}=$ normal, $\mathrm{B}=$ bradycardia, $\mathrm{LAH}=$ left anterior hemiblock, VPB $=$ ventricular premature beat, $\mathrm{RBBB}=$ right bundle branch block, $\mathrm{AF}=$ atrial fibrillation, and AVB = auriculo ventricular block.

$\dagger$ DI, DII, DII, MI, MII, and MIII = abnormal length or enlargement of the colon according to the degree of hypertrophy.

$\neq$ Zymodeme numbering according Tibayrenc and others. ${ }^{8}$ 
sented a cardiac and/or digestive pathology. Both groups of zymodemes were found significantly pathogenic $\left(\chi^{2}\right.$ test with the null hypothesis being that the zymodemes are non-pathogenic. For patients infected by zymodemes 7,19 , or $20, x^{2}=$ 23.33, $P<10^{-3}$, and $\mathrm{df}=1$. For patients infected by zymodeme $39, \chi^{2}=9.5, P<10^{-2}$, df $=1$. We did not find any statistical differences between the 2 groups regarding the alternative presence/absence of pathogenicity $\left(\chi^{2}=0.19, P>\right.$ $0.30, \mathrm{df}=1$ ). Numbers of patients from each clinical group were too small to allow a statistical study of a possible specific association between a given zymodeme and the existence of either cardiopathy or a megacolon.

\section{DISCUSSION}

\section{Clinical and serological features of Chagas' disease in Bolivia}

The high rates of positive serology observed in the 3 endemic areas studied clearly shows the extensive distribution of Chagas' disease in Bolivia. We observed important differences in the index of serology between Chiwisivi and Salinas, and between the rates of cardiopathy in the 3 areas. The different anatomic changes observed in Bolivian patients have already been reported in the framework of Chagas' disease; however, we observed a particularly low frequency of megaoesophagus in this country compared to the frequencies observed in endemic areas of Bahia, Goias, ${ }^{13,14}$ and Minas Gerais. ${ }^{15}$ These results confirm the heterogenity of the different anatomic changes seen in Chagas' disease endemic areas. ${ }^{1}$

\section{Zymodeme variability: human hosts from Bolivia}

Extensive isoenzyme studies of $T$. cruzi isolated from $T$. infestans, the main domestic vector in Bolivia, have been done. ${ }^{12}$ We report zymodeme variability among strains isolated from humans in the same country. Our results show that the zymodeme variability is comparable among strains isolated from triatomine insects ${ }^{12}$ and from humans. If we compare strains isolated from triatomine insects with strains isolated from humans in the areas of Cochabamba, Sucre, and SantaCruz, the numbers of strains pertaining to zymodemes 19 and 20 and to zymodeme 39 are not significantly different $\left(\chi^{2}=2.22\right.$, df $=1, P>$
0.05). This strongly suggests a lack of selection, either by humans or by triatomine bugs, for any of the 3 zymodemes.

Genetic and patristic distances calculated between the zymodemes studied here, which represent a geographically limited sample, reveal high genetic variability (Table 5). Clustering the zymodemes into a few, strictly separated subgroups was impossible (Fig. 2). This confirms previous data. $^{8}$

\section{Close sympatrical circulation of Bolivian zymodemes}

The existence of mixtures of $\geq 2$ different zymodemes has been reported from Bolivia in triatomine vectors as well as in humans. ${ }^{6,12,16} \mathrm{We}$ report here new cases of mixed human infections and describe several cases of double infections with zymodemes genetically unrelated ${ }^{8}(20$ and 39,40 and 20 ) or, in contrast, closely related to each other ${ }^{8}$ (20 and 7). Thus, mixed infections appear to be common in Bolivia. This phenomenon has not been noted neither in Brazilian nor in Chilean endemic areas. ${ }^{17,18}$ This may be because other authors have used different sampling, culture, and electrophoresis techniques. Tibayrenc and others, using techniques comparable to the present ones, have described cases of mixed strains in Chilean samples. ${ }^{7,8}$

\section{Zymodemes and pathology}

Serological and clinical data of the present study have shown important differences between the Chiwisivi area and the Camiri and Salinas areas, which are only $50 \mathrm{~km}$ apart. It is worth noting that previous studies have identified very different zymodeme variability in the Chiwisivi and Camiri regions. Of 141 strains of $T$. cruzi isolated from $T$. infestans in Chiwisivi, $99 \%$ presented a similar isozyme profile corresponding to zymodeme 9. In Camiri, a much higher range of genetic variability has been recorded: 5 different zymodemes from only 15 strains isolated from T. infestans (Table 1). ${ }^{12}$ This observation is consistent with the working hypothesis of specific pathogenic properties of the zymodemes, but has of course to be examined on a broader scale.

In view of the clinical diversity of Chagas' disease and the presence in Bolivia of 2 radically dissimilar, widespread zymodemes, we decided to check for a possible statistical association be- 
tween pathologies and zymodemes. Such an association was impossible to evidence, which confirms our previous results. ${ }^{16}$ Moreover, the 3 more frequent zymodemes $(19,20$, and 39$)$ did not show significant differences in their pathogenicity, and have all been found in patients presenting cardiac or gastrointestinal (megacolon) or associated alterations. Although the present sample is too small for statistical analysis of a possible association between zymodeme variability and specific pathological changes, these results suggest an absence of strict association. Nevertheless, they do not rule out the hypothesis of zymodeme pathogenic specificity. Indeed, several methodological difficulties could explain our negative results. For instance, xenodiagnosis, culture, and host immune response could act as "filters," which could select given parasite subpopulations from a mixed infection, in which case the parasite population studied by isozymes would not be a true picture of the 1 from the patient. Furthermore, mixed infections of at least 2 different zymodemes are very frequent in Bolivia (Table 3 ) and are probably heavily underestimated, which means that human Chagas' disease in this country is definitely not a pure model for studying the problem of zymodeme pathogenic specificity.

The question of the clinical consequences of $T$. cruzi genetic variability is still an unanswered one. In natural cycles, valuable circumstantial evidence could come from extensive comparisons of ecologically similar regions, each harboring a different type of zymodeme. To avoid biases due to culture and xenodiagnosis, zymodeme specific DNA probes would be extremely valuable. Such studies should be compared to experimental works on animals involving statistically representative samples of cloned strains pertaining to various zymodemes.

Acknowledgments: We are indebted to Gerardo Antezana and Yves Carlier, heads of the Instituto Boliviano de Biologia de Altura, Bolivia, who permitted these studies. We thank François Bonhomme from the University des Sciences et Techniques du Languedoc, Montpellier, France, for valuable help in phylogenetic analysis of zymodemes.

Financial support: The French Technical Cooperation Program.

Authors' addresses: S. F. Brenière and M. Tibayrenc, Laboratoire de Génétique des parasites et des vecteurs, ORSTOM, BP 5045, 34032 Montpellier Cedex, France. R. Carrasco, S. Revollo, and G. Aparicio, IBBA, Cas- illa 641, La Paz, Bolivia. P. Desjeux, World Health Organization, 1211, Geneva, 27-Switzerland.

Reprint requests: S. F. Brenière, Laboratoire de Génétique des parasites et des vecteurs, ORSTOM, BP 5045, 34032 Montpellier Cedex, France.

\section{REFERENCES}

1. Miles MA, Cedillos RA, Povoa MM, de Souza AA, Prata A, Macedo V, 1981. Do radically dissimilar Trypanosoma cruzi strains (zymodemes) cause Venezuelan and Brazilian forms of Chagas' disease? Lancet 1: 1338-1340. UI:81219737

2. Breniere SF, Carrasco R, Miguez H, Lemesre JL, Carlier Y, 1985. Comparisons of immunological tests for serodiagnosis of Chagas disease in Bolivian patients. Trop Geogr Med 37: 231238. UI: 86071532

3. WHO, 1974. Aspectos clinicos de la enfermedad de Chagas. Informe de la reunion conjunta WHO/ OPS de investigadores. Bol Ofic Sanit Panamerican 77: 141-158.

4. Ferreira-Santos R, 1961. Aperistalsis of the esophagus and colon (megaesophagus and megacolon) etiologically related to Chagas disease. Am J Dig Dis 6: 700-726.

5. Tibayrenc M, Echalar L, Desjeux P, 1982. Une methode simple pour obtenir directement des isolats de Trypanosoma cruzi a partir du tube digestif du triatome vecteur. Cah ORSTOM ser Ent Med Parasitol 3: 187-188.

6. Tibayrenc M, Cariou MI, Solignac M, Dedet JP, Poch O, Desjeux P, 1985. New electrophoretic evidence of genetic variation and diploidy in Trypanosoma cruzi the causative agent of Chagas disease. Genetica 67: 223-230.

7. Tibayrenc M, Ayala FJ, 1988. Isoenzyme variability of Trypanosoma cruzi the agent of Chagas disease: genetical, taxonomical and epidemiological significance. Evolution 42: 277-292.

8. Tibayrenc M, Ward P, Moya A, Ayala FJ, 1986. Natural populations of Trypanosoma cruzi, the agent of Chagas disease, have a complex multiclonal structure. Proc Natl Acad Sci USA 83: 115-119. UI:86094325

9. Nei M, 1972. Genetic distances between populations. Amer Natur 106: 282-292.

10. Farris JS, 1970. Methods for computing Wagner trees. Syst Zool 19: 83-92.

11. Felsenstein J, 1978. Cases in which parsimony or compatibility methods will be positively misleading. Syst Zool 27: 401-410.

12. Tibayrenc M, Hoffmann A, Poch O, Echalar L, Le Pont F, Lemesre JL, Desjeux P, Ayala FJ, 1986. Additional data on Trypanosoma cruzi isozymic strains encountered in Bolivian domestic transmission cycles. Trans $R$ Soc Trop Med Hyg 80 : 442-447. UI:87095218

13. Alecrim WD, Castro CN, Rezende J, Macedo V, Prata A, 1977. Estudo da dinamica esofagica entre duas areas endemicas da doenca da Chagas. An Cong Soc Brazil Med Trop: 24.

14. Mota E, Todd CW, Maguire JH, Portugal D, San- 
tana O, Ribeiro Filho R, Sherlock IA, 1984. Megaesophagus and seroreactivity to Trypanosoma cruzi in a rural community in northeast Brazil. Am J Trop Med Hyg 33: 820-826. UI: 85020435

15. Dias JCP, Camacho LAB, Silva JC, Magalhaes JS, Krieger H, 1983. Esofagopatia Chagasica na area endemica de Bambui, M.G. Brasil. Rev Soc Brasil Med Trop 16: 46-57.

16. Breniere SF, Tibayrenc M, Antezana G, Pabon J, Carrasco R, Selaes H, Desjeux P, 1985. [Preliminary results suggesting a tenuous or nonexistent relation between clinical forms of Chagas disease and isoenzyme strains of Trypanosoma cruzi]. C R Acad Sci [III] 300: 555-557. UI: 85253968
17. Miles MA, Povoa MM, de Souza AA, Lainson R, Shaw JJ, Ketteridge DS, 1981. Chagas's disease in the Amazon Basin: II. The distribution of Trypanosoma cruzi zymodemes 1 and 3 in Para State, North Brazil. Trans $R$ Soc Trop Med Hyg 75: 667-674. UI:82130094

18. Apt W, Aguilera X, Arribada A, Gomez L, Miles MA, Widmer G, 1987. Epidemiology of Chagas' disease in northern Chile: isozyme profiles of Trypanosoma cruzi from domestic and sylvatic transmission cycles and their association with cardiopathy. Am J Trop Med Hyg 37:302307. UT:88021511 
CHAGAS' DISEASE IN BOLIVIA: CLINICAL AND EPIDEMIOLOGICAL FEATURES AND ZYMODEME VARIABILITY OF TRYPANOSOMA CRUZI STRAINS ISOLATED FROM PATIENTS

S. F. Brenière, R. Carrasco, S. Revollo, G. Aparicio, P. DEsJeux, AND M. TIBAYRENC

Made in United States of America

Reprinted from THE AMERICAN JOURNAL OF TROPICAL MEDICINE AND HYGIENE Vol. 41, No. 5, November 1989

Copyright $@ 1989$, The American Society of Tropical Medicine and Hygiene

ORSTOM Fonds Documentaire

25 JAN. 9989

No: $31.258 \mathrm{me} \times 1$

Cote $\dot{B}$

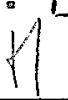

